CLAUDIA ANGÉLICA REYES SARMIENTO

ÁREA TEORÍA E HISTORIA DEL DISEÑO GRÁFICO

ESCUELA DE DISEÑO, FOTOGRAFÍA

Y REALIZACIÓN AUDIOVISUAL

UNIVERSIDAD JORGE TADEO LOZANO

BOGOTÁ, COLOMBIA

CLAUDIAA.REYES@UTADEO.EDU.CO

Financiamiento

Dirección de investigaciones de la

Universidad Jorge Tadeo Lozano, a través

de una convocatoria interna de investigación.

Fecha de recepción: 25/03/2019

Fecha de aceptación: 30/05/2019

Cómo citar: Reyes Sarmiento, C. (2019)

Imprenta del sótano: colección de clisés de la

Biblioteca Nacional de Colombia.

RChD: creación y pensamiento, 4(6), 1-1]

DOI: 10.5354/0719-837X.2019.52604

Revista Chilena de Diseño,

RChD: creación y pensamiento

Universidad de Chile

2019, 4(6)

http://rchd.uchile.c

\section{Imprenta del sótano: colección de clisés de la Biblioteca Nacional de Colombia}

\author{
Print of the Basement: Collection of Clises \\ of the National Library of Colombia
}

Resumen. El presente artículo es resultado del proyecto de investigación titulado "Imprenta e impresiones en la Biblioteca Nacional de Colombia: análisis gráfico, histórico, patrimonial y estético de la colección de clisés de la Biblioteca Nacional de Colombia y de las publicaciones en las que circularon (1930 - 1960)", desarrollado entre la Universidad Jorge Tadeo Lozano y la Biblioteca Nacional de Colombia. El proyecto obtuvo el financiamiento de la Dirección de investigaciones de la Universidad Jorge Tadeo Lozano, a través de una convocatoria interna de investigación.

En el año 2015 se encontraron algunas planchas metálicas de impresión en la Biblioteca Nacional de Colombia. Desde entonces, se ha generado gran interés en torno a una serie de imágenes, escudos, fotograbados, textos y firmas (279 en total), que dan cuenta de una parte de la historia de la institución y del país. Estos hallazgos se deben a que en el edificio de la Biblioteca funcionó la Imprenta Nacional de Colombia, cuyos talleres se encontraban en el sótano. Es decir, que desde allí se produjeron diversas publicaciones que enriquecieron nuestro patrimonio bibliográfico.

Los clisés de impresión son objetos susceptibles de investigación histórica, con lo cual se amplían las posibilidades de trabajar con fuentes documentales, que al mismo tiempo son documentos históricos, para reconstruir el pasado y presente de la sociedad colombiana, la historia del diseño y las publicaciones periódicas, entre otros.

Palabras clave: Biblioteca Nacional de Colombia, clisé, historia del diseño, patrimonio bibliográfico, patrimonio gráfico.

Abstract. This article is the result of a research project entitled "Print and printing in the National Library of Colombia: Graphic, Historical, Patrimonial and Aesthetic Analysis of the Collection of Clichés of the National Library of Colombia and the Publications in which They Circulated (1930 - 1960)", developed between the Jorge Tadeo Lozano University and the National Library of Colombia. In 2015, some metallic printing plates were found in the National Library of Colombia. Since then, great interest has been generated around a series of images, shields, photogravures, texts and signatures (279 in total), which account for a part of the history of the institution and the country. These findings are due to the fact that the National Printing House of Colombia operated in the Library building, whose workshops were in the basement. That is to say that from there several publications were produced that enriched our bibliographic heritage.

Print clichés are objects susceptible of historical research, which expands the possibilities of working with documentary sources, which at the same time are historical documents, to reconstruct the past and present of Colombian society, the history of design and publications periodic, among others.

Keywords: Bibliographic heritage, cliche, graphic heritage, history of design, National Library of Colombia. 


\section{Introducción}

Este texto es el resultado del proceso adelantado en el proyecto de investigación titulado: "Imprenta e impresiones en la Biblioteca Nacional de Colombia: análisis gráfico, histórico, patrimonial y estético de la colección de clisés de la Biblioteca Nacional de Colombia y de las publicaciones en las que circularon (1930 - 1960)", vinculado al Grupo de Investigación en Estudios de la Imagen, adscrito a la Facultad de Artes y Diseño de la Universidad Jorge Tadeo Lozano, el cual se ha desarrollado en convenio con la Biblioteca Nacional de Colombia.

El grupo de trabajo estuvo compuesto por profesionales de diferentes áreas como Diseño gráfico, Estudios literarios, Análisis del discurso y Artes visuales. Además, contó con la participación de estudiantes del Semillero de investigación en Teoría e Historia del Diseño de la Escuela de Diseño, Fotografía y Realización Audiovisual de la Universidad Jorge Tadeo Lozano. El objetivo principal del proyecto es analizar desde las perspectivas histórica, estética, patrimonial y gráfica la colección de clisés encontrados en la Biblioteca Nacional de Colombia y las publicaciones en las que circularon entre 1930 y 1960, para lo cual fue necesario trabajar con fuentes primarias, como los clisés de impresión, fuentes documentales, como las publicaciones periódicas en las que circularon las imágenes de las piezas metálicas y fuentes del núcleo relacional.

Se tratarán aspectos relacionados con los componentes que se consideraron en la primera fase del proyecto, desarrollada entre el 2015 y el 2016, la cual se concentró en la recolección, clasificación, catalogación y análisis de las piezas encontradas. A partir de dicha fase preliminar, se estableció una estructura de trabajo que se enfocó en el análisis de las piezas de metal y de las publicaciones desde las perspectivas ya mencionadas.

Es interesante entender cómo los clisés se articulan con el estudio de las imágenes, su producción y el sentido simbólico que probablemente adquirieron en los libros, las revistas y las demás piezas gráficas en los que circularon, pero al mismo tiempo es necesario comprender cómo estas piezas de metal, utilizadas una y otra vez o en otros casos fueron producidas pero nunca se usaron, componen el acervo patrimonial e histórico de nuestro país y del diseño gráfico. Así mismo, cómo el Diseño es parte de la cultura material y visual, que mediante productos y sistemas ha contribuido a la construcción material de nuestro país.

Para abordar el proceso inicial, motivo de este texto, se tuvieron en cuenta los siguientes elementos:

1. Componentes temáticos y aspectos metodológicos: lugares de observación e Identificación de la colección.

2. Componente histórico.

3. Componente patrimonial en el que se enmarcan los clisés, entendidos estos últimos como una plancha o grabado empleado en procesos de impresión.

\section{Componentes temáticos y aspectos metodológicos: lugares de observación, identificación y reconocimiento de la colección}

La colección está compuesta por 276 clisés distribuidos entre imágenes, escudos, fotograbados, textos y firmas, los cuales circularon en textos que fueron impresos desde los años treinta, cuando en el edificio de la Biblioteca Nacional de Colombia funcionaba la imprenta del Archivo Nacional y de la Biblioteca. 


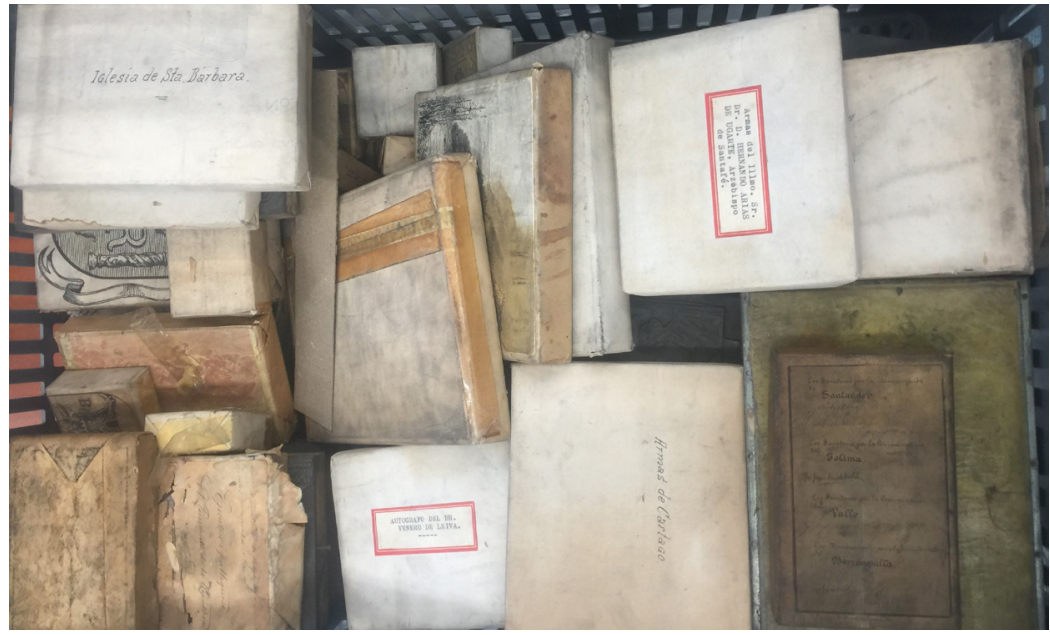

La riqueza visual y patrimonial de la colección es muy importante, ya que no solo da cuenta de la historia de una de las instituciones más reconocidas en Colombia por el manejo, conservación y protección del acervo bibliográfico y patrimonial colombiano, sino que desde la perspectiva histórica es un hallazgo destacado. Por otro lado, dicha colección es una muestra importante de la historia del Diseño colombiano, la cual puede ser estudiada desde áreas como los medios editoriales, la tipografía, la composición, la historia y la producción de imágenes, entre otras. Dentro de la identificación de la colección se tuvieron en cuenta las siguientes etapas:

\section{a. Reconocimiento de la colección}

En esta etapa se hizo una primera aproximación a las piezas (Figuras 1 y 2), las cuales se encontraron llenas de polvo en una de las cubiertas de la Biblioteca, se presume que llevaban varios años ocultas. Algunas estaban envueltas en papel y con la muestra de la impresión, mientras que otras estaban sin envoltura. La mayoría de las piezas se utilizó para la impresión de alguna imagen o texto, pero también se evidenció que algunas de ellas, aunque se produjeron, no se llegaron a usar.

\section{b. Preclasificación y registro}

Los clisés se clasificaron de acuerdo con aquello que se observó inicialmente, es decir, a partir de aspectos como el tipo, imagen o texto, formas y formatos, entre otros. Con esto se identificaron tres tipos: clisés con letras y textos, con imágenes (ilustradas o fotográficas), partituras y clisés en los que aparecían los dos elementos (texto e imagen).

Las categorías de clasificación se establecieron a partir de los rasgos comunes de las piezas, no solo a nivel formal sino principalmente en cuanto a su contenido. El proceso arrojó el reconocimiento de un primer grupo, que se refiere a una "Campaña Nacional contra el Analfabetismo". Cada pieza contiene una ilustración asociada a una letra del abecedario, a partir de un objeto y su respectiva división silábica. Además, en una esquina se encuentra el texto que identifica la campaña.

Precisamente este grupo entraña una dificultad: no se ha podido identificar en qué publicación se utilizaron las piezas. Por la misma razón, no ha sido

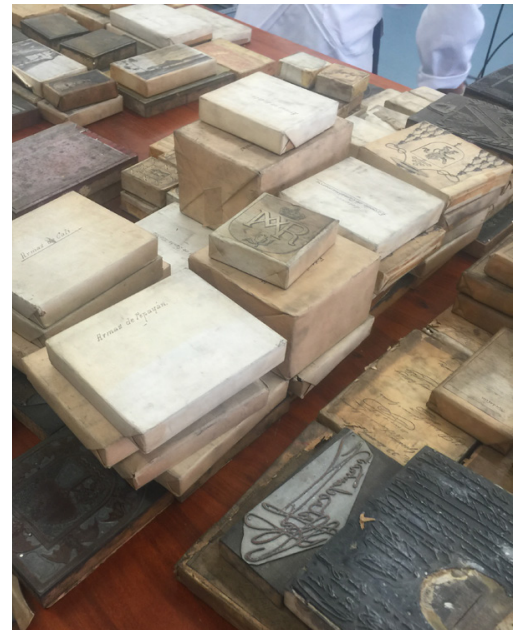

Figuras 1 y 2. Estado de las piezas encontradas en la cubierta de la Biblioteca Nacional de Colombia. 
posible definir en qué época fueron impresas. La hipótesis que se maneja las relaciona con las estrategias educativas desarrolladas en el marco de la hegemonía liberal durante los años treinta del siglo XX, cuando a través del Ministerio de Educación Nacional se procuró mejorar la cobertura en los niveles básicos de la educación. Este es el caso de la Biblioteca Aldeana, creada en el marco de la Campaña de Cultura Aldeana:

El propósito era ofrecer una educación que generara una manera de vivir más "civilizada" que redundara en el mejoramiento de la calidad de vida de las comunidades, la transformación de valores ideológicos y el desarrollo de nuevos hábitos y costumbres alimenticias, de higiene, nutrición y estética. (Herrera, 1993, p. 7)

Si es posible verificar su carácter como herramienta de la política educativa pública de este periodo, será posible analizar la "Campaña Nacional contra el analfabetismo" como muestra de una iniciativa educativa y cultural que parte de un modelo de desarrollo basado en la industrialización (cimiento de las reformas liberales). En este caso, es evidente en la producción en serie de publicaciones con fines educativos y culturales, en las que el Diseño gráfico fue utilizado como apoyo a los lineamientos pedagógicos que estructuraban la campaña. Como producto, la cartilla y los clisés utilizados en su publicación son susceptibles de ser analizados a partir de su carácter patrimonial, desde la historia de la educación, el desarrollo del diseño y las técnicas de impresión en el país.

El segundo grupo está compuesto por un alfabeto de veintiuna letras, ya que faltan tres $(e, k, w)$. Estas letras circularon como iniciales de algunos artículos en la Revista del Archivo Nacional entre 1936 y 1937. La revista se imprimió en la sede de la Biblioteca Nacional de Colombia. Por otro lado, las características visuales de cada letra llevan a considerar que probablemente fueron diseñadas por Sergio Trujillo Magnenant, ilustrador, artista y uno de los pioneros del Diseño gráfico colombiano. En este grupo también se ubican textos con firmas, textos y autógrafos que en su mayoría circularon en la misma revista. El tercer grupo está compuesto por una serie de escudos antiguos que fueron impresos en tres volúmenes de un texto titulado Genealogías del Nuevo Reino de Granada: dedicado al ilustrísimo señor doctor don Melchor de Liñán y Cisneros Obispo de Popayán, de Charcas, del Consejo de su Majestad, Gobernador y Capitán General del Nuevo Reino de Granada, y Presidente de su Real Chancillería y su Visitador Vol. I - II (1943 - 1944). Estos volúmenes son ediciones facsimilares del texto original que se ubica en el Fondo Antiguo de la Biblioteca. El primer volumen de este texto está compuesto por 492 páginas en folio, las primeras 58 hacen referencia a temas sobre la heráldica. Otra parte del estudio se concentra en algunas exploraciones y conquistas del territorio colombiano, mientras que otra parte muestra algunos catálogos basados en archivos del Nuevo Reino. Además, se muestra una relación histórico-geográfica de las ciudades y villas del Nuevo Reino. Luego, aparece un capítulo dedicado a la historia religiosa en este territorio.

El segundo volumen tiene 500 folios y hace referencia a los árboles genealógicos de cuarenta conquistadores y sus descendientes: 

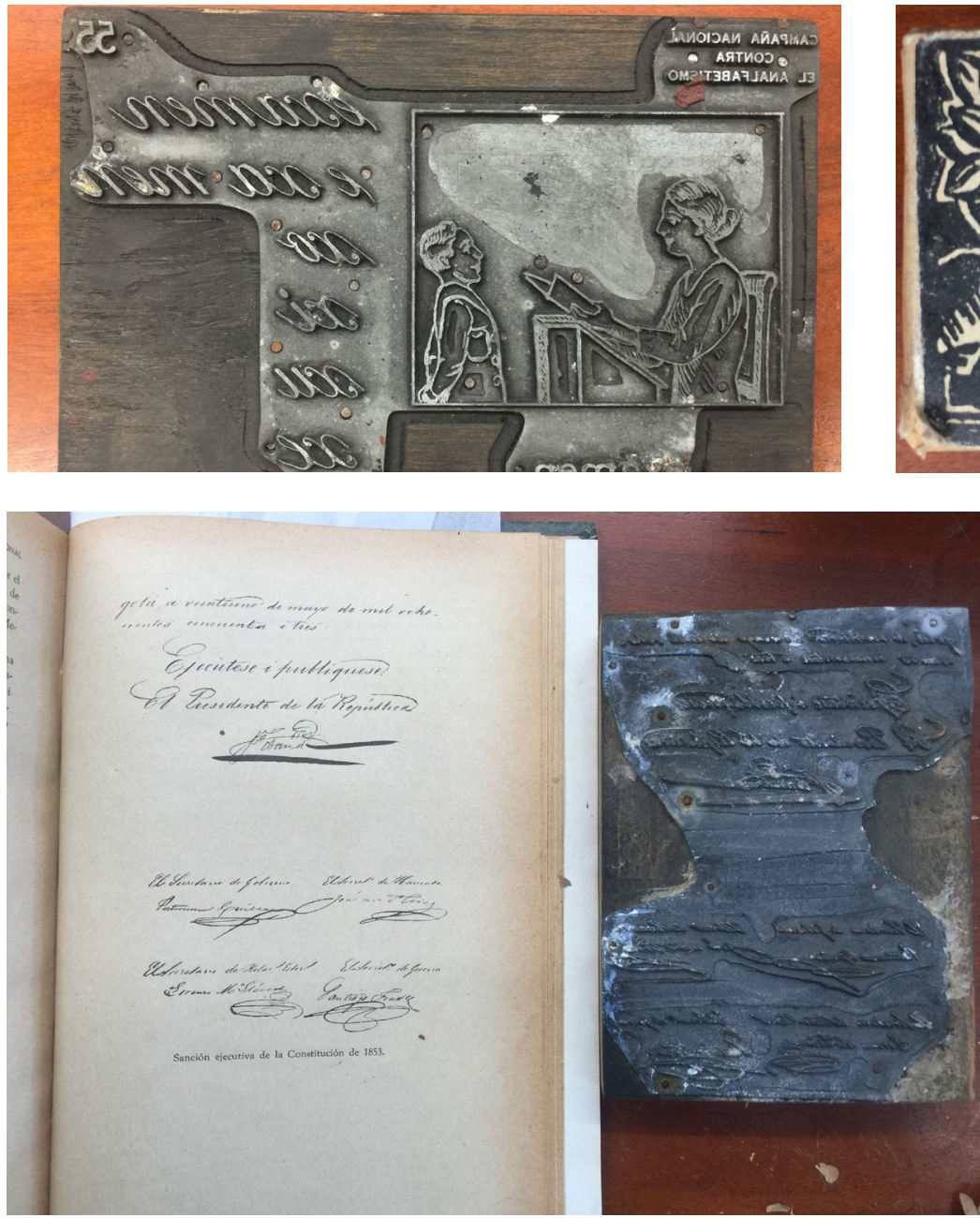

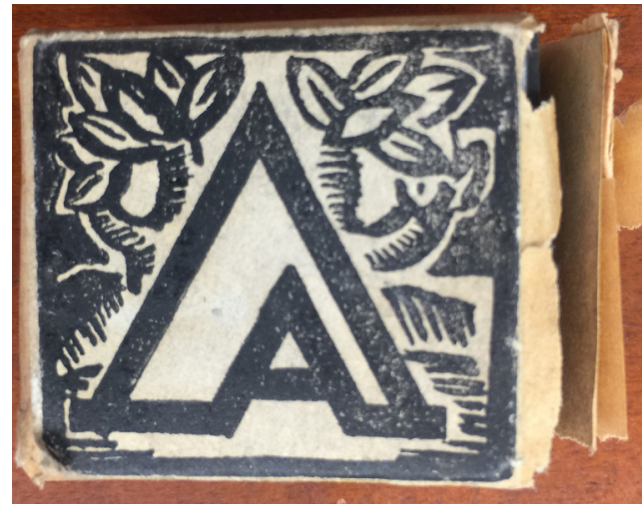

Figura 3. Clisé "Campaña Nacional contra el Analfabetismo". Biblioteca Nacional de Colombia. Texto no identificado. $14.5 \mathrm{~cm} \times 10 \mathrm{~cm}$.

Figura 4. Clisé empacado de la letra "a" empleado en la impresión de letras capitales de la Revista del Archivo Nacional. Año II No. 13 - 14 (enero-febrero de 1937). $4 \mathrm{~cm} \times 3.5 \mathrm{~cm}$.

Figura 5. Revista del Archivo Nacional, Año I No. 1-2 (enero-febrero de 1936, p. 73). Clisé fundido metal. $10.5 \mathrm{~cm} \times 14.2 \mathrm{~cm}$.

(...) los dos tomos impresos de las Genealogías se han convertido en una de las rarezas bibliográficas más exquisitas, no digamos de nuestra propia bibliografía, sino de la bibliografía universal. Los contados ejemplares que de ellos existen háyanse encarcelados en ciertas famosas bibliotecas o en manos de algún dichoso bibliófilo o bibliómano, y cada día que pasa se siente aún más la ausencia de una obra de consulta tan necesaria para los historiadores. (Flórez de Ocariz, 1994, p. 21)

El cuarto grupo se compone de una serie de fotograbados que hacen referencia a la ciudad de Villavicencio, imágenes de la Revista Senderos, la Revista del Archivo Nacional y Hojas de Cultura Popular, publicadas por la imprenta de la Biblioteca.

A continuación, se observan los grupos y el número de clisés asociados:

- “Campaña Nacional contra el Analfabetismo": veintiocho clisés compuestos de imagen, número e identificador. Los textos que acompañan la imagen son letras cursivas, mientras que los nombres de las imágenes son serifadas (Figura 3). 

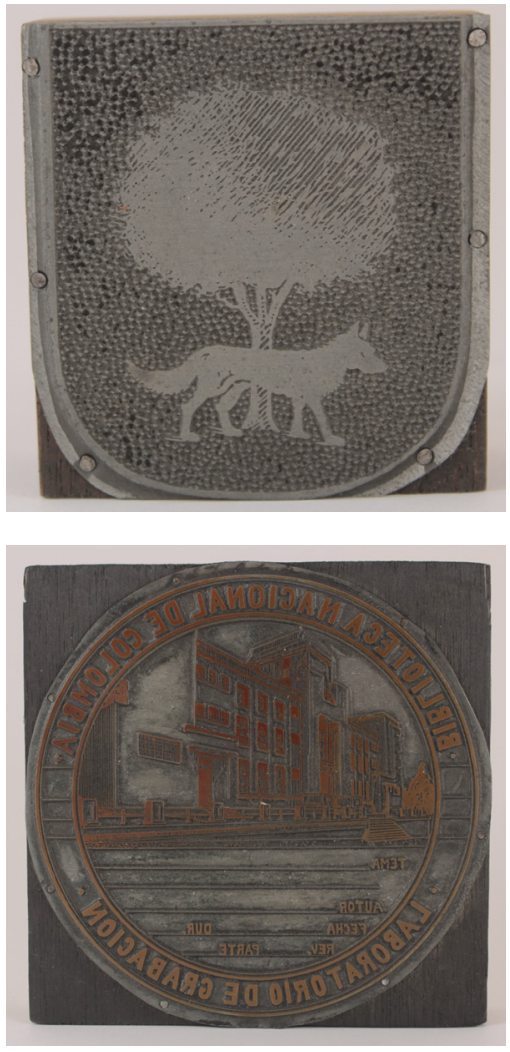

Figura 6. Genealogías del Nuevo Reino de Granada: dedicado al ilustrísimo señor doctor don Melchor de Liñán y Cisneros Obispo de Popayán, de Charcas, del Consejo de su Majestad, Gobernadory Capitán General del Nuevo Reino de Granada, y Presidente de su Real Chancillería y su Visitador. Vol. II (1944). P. 135. Clisé de $5.1 \mathrm{~cm} \times 5.4 \mathrm{~cm}$. Figura 7. Clisé utilizado en: Conferencia Menéndez y Pelayo (recurso electrónico, 1956). $10.6 \mathrm{~cm} \times 10.8 \mathrm{~cm}$.
- Alfabeto compuesto por veinticuatro piezas (Figura 4). Sin embargo, no todas fueron utilizadas en impresión, ya que algunas estaban nuevas. Cada una de las letras está acompañada de una ilustración.

- Textos con firmas (Figura 5): treinta clisés con textos que llevan firmas y son de varias ciudades de Colombia.

- Autógrafos: cuatro piezas de autógrafos en quirografía.

- Escudos de armas del libro Genealogías del nuevo Reino de Granada (Figura 6) y Heráldica eclesiástica: 114.

- Sellos de la Biblioteca Nacional de Colombia (Figura 7): dos.

- Imágenes de Villavicencio: cuatro.

- Imágenes de paisajes y espacios rurales: cinco.

- Imágenes de Villa de Leyva y otras ciudades e iglesias: diecisiete.

- Imágenes de fotograbados con diversos temas (Figura 8): doce.

- Mapas: dos.

- Retratos (Figura 9): trece.

- Clisés con imágenes de la Constitución Política de 1886: dieciséis.

- Partituras: cinco.

\section{Componente histórico}

Desde su creación, la Biblioteca Nacional de Colombia ha tenido como misión: "garantizar la recuperación, preservación y acceso a la memoria colectiva del país, representada por el patrimonio bibliográfico y hemerográfico en cualquier soporte físico" (Biblioteca Nacional de Colombia, 2015). Luego de que se estableciera el estatuto de la Biblioteca, en septiembre de 1934, bajo la dirección de Samper Ortega se generaron estrategias que buscaban el fomento de la cultura y la educación:

En los planes del Ministerio de Educación Nacional sobre impulso de la cultura en todos sus ramos, la Biblioteca Nacional deberá servir de sistema circulatorio al libro del país y al pensamiento colombiano en el exterior, suplir las deficiencias de la escuela ante aquellos que no puedan concurrir a ella, levantar el nivel mental de las clases inferiores y cooperar al buen resultado de los esfuerzos individuales, ayudando a los colombianos a orientarse en el estudio como medio para perfeccionar la personalidad y, en consecuencia, a capacitarse mejor para la acción creadora de la riqueza pública y de la nacionalidad. Tan variados fines imponen a la Biblioteca una actitud vital y agitadora, fácil de alcanzar prosperando los departamentos que hoy tiene en embrión y con los cuales ha esbozado sus deseos de mantener las ideas en movimiento y de difundirlas por todos los medios a su alcance. Tales departamentos son los siguientes:

a) El departamento de librería.

b) El departamento editorial.

c) El departamento de cinematografía educativa.

d) El departamento de radiodifusión.

e) El departamento de información y propaganda. (Hernández y Carrasquilla, 1977, pp. 257, 258)

El departamento editorial fue el encargado de producir publicaciones del Ministerio de Educación Nacional, así como otros textos. Esta producción se 
vinculó con la imprenta que tenía la Biblioteca desde el momento en el que se inaugura el nuevo edificio bajo la dirección de Daniel Samper. La imprenta se ubicó en los sótanos, incluidos los talleres de encuadernación y fotograbado. El compromiso de la Biblioteca Nacional de Colombia con procesos asociados a proyectos educativos se ha evidenciado en diferentes momentos de su historia. Un ejemplo de ello se encuentra en la Memoria presentada al Congreso de 1941 por el ministro de Educación Guillermo Nanetti, donde se hace referencia a diferentes estrategias para promover el desarrollo cultural y social de la población colombiana. Una de estas estrategias se adoptó en la Biblioteca Nacional bajo la dirección de Enrique Uribe White, quien, con el objetivo de "dar a esta entidad un carácter dinámico de organismo propulsor de la cultura nacional” (Ministerio de Educación Nacional, 1941, p. 36), decidió crear e instalar un taller de imprenta para la impresión del periódico de $L a$ Escuela Normal, las obras de la Biblioteca del maestro, dos libros mensuales de autores colombianos, documentos del Archivo, manuscritos inéditos, los trabajos del Ateneo de Altos estudios y las obras de Rufino José Cuervo. Al respecto, Uribe White (1941) explica:

Se ha considerado que poca o ninguna labor se realiza con publicar un libro por año; que a los colombianos hay que ponerles en las manos libros baratos en suficiente número, con suficiente intensidad y tenacidad de intención, para obligarlos a leer. $Y$ que la cultura colombiana no se difunde en el continente sino por medio del canje y del libro bien editado puesto al alcance de todos. Se espera fundadamente que el pie de imprenta Biblioteca Nacional sea garantía de seriedad, corrección y nitidez. (Ministerio de Educación Nacional, 1941, p. 48)

En síntesis, para cumplir con dichos propósitos educativos y culturales, la imprenta se ubicó en la Biblioteca desde la inauguración de su nuevo edificio. En ella se grabaron textos como:

1. La revista Senderos (1935).

2. La revista del Archivo Nacional de Colombia (1941).

3. Las Genealogías del Nuevo Reino de Granada Volumen I y II (1955).

4. Heráldica colombiana (1952).

5. Monografía histórica sobre Villavicencio (1943).

6. Texto sobre los cementerios de Bogotá (1931).

7. Hojas de Cultura Popular (1947).

8. Biblioteca Aldeana (1941).

Por otra parte, el Estatuto fijó las funciones del departamento editorial:

a) La publicación de los catálogos y revistas de la Biblioteca y las publicaciones del Ministerio de Educación Nacional.

b) La renovación de los catálogos de la Biblioteca con la necesaria frecuencia para que siempre estén prestando un servicio eficaz.

c) La publicación de colecciones colombianas encaminadas a recoger ordenadamente todo aquello que la mentalidad colombiana haya producido y que merezca ser llevado al conocimiento de las generaciones venideras, lo que sirva para la historia y lo que tienda a despertar inquietudes convenientes a la plasmación de la nacionalidad.
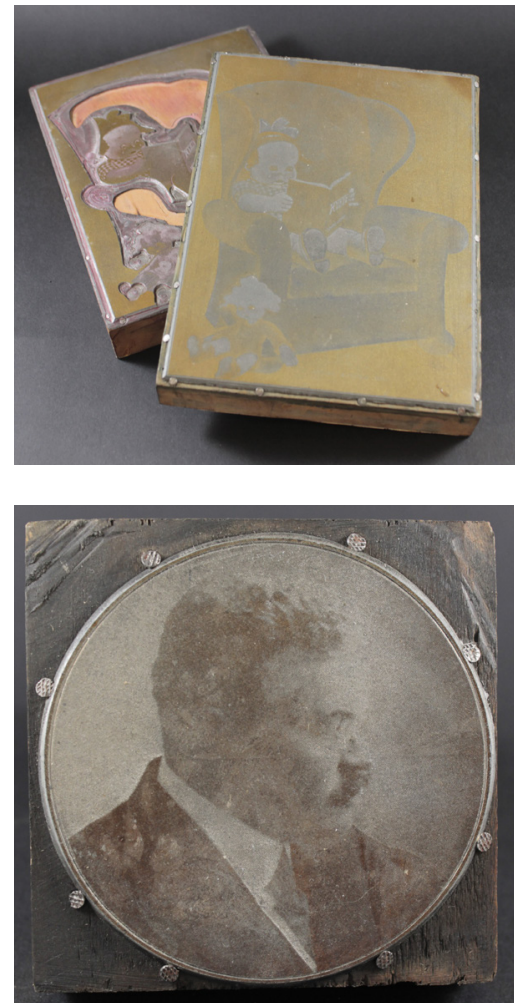

Figura 8. Clisé fundido metal. Texto sin identificar. $12.3 \mathrm{~cm} \times 16.7 \mathrm{~cm}$. Ilustración infantil.

Figura 9. Fotograbado. D. Manuel Maria Malario. Texto sin identificar. $8.6 \mathrm{~cm} \times 8.7 \mathrm{~cm}$. 
Figura 10. Catálogo virtual Biblioteca Nacional de Colombia. Consolidación de la Biblioteca Nacional (1820-1886)

Figura 11 y 12. Catálogo virtual Biblioteca Nacional de Colombia. La Biblioteca de la República Liberal (1930-1934)
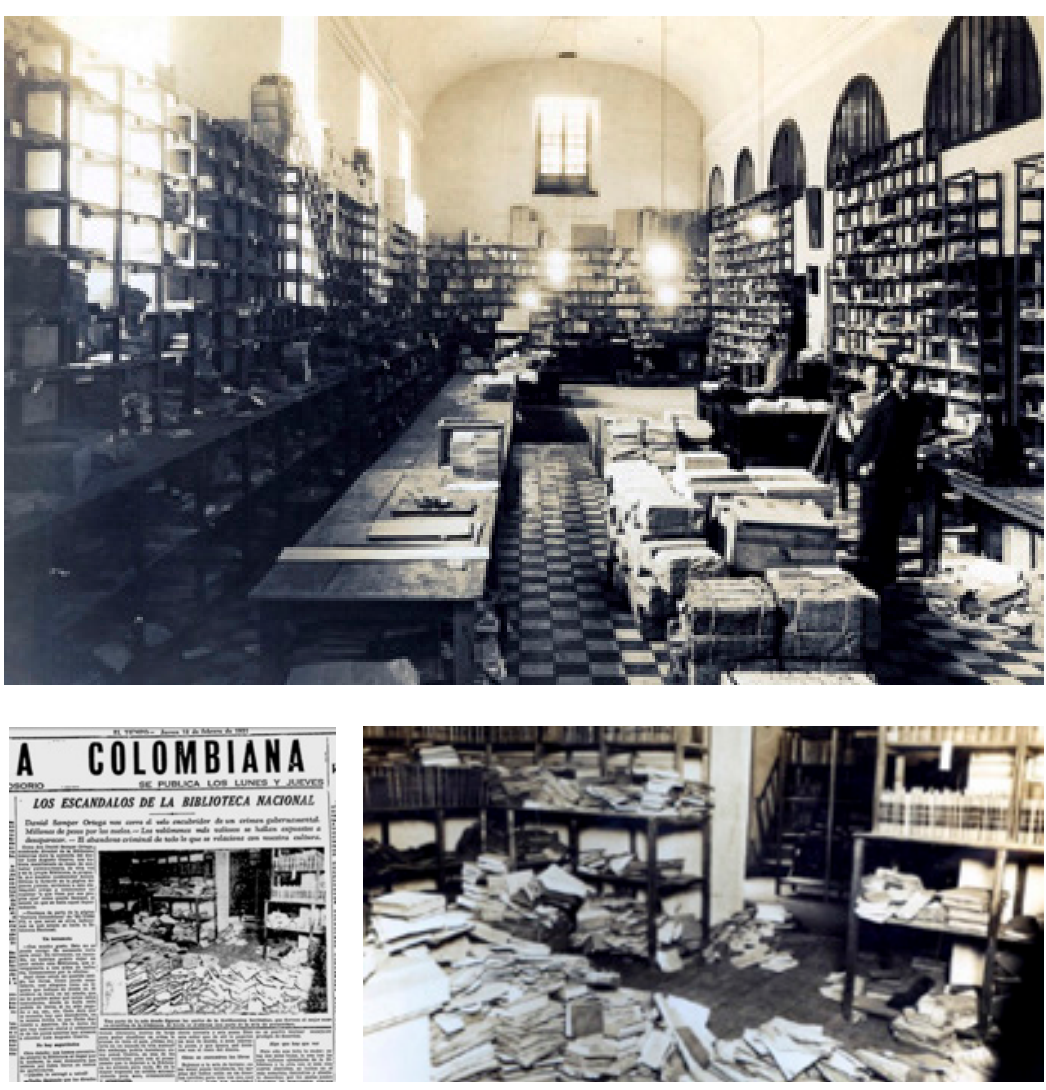

d) El suministro a las misiones ambulantes de las cartillas que necesiten para complementar y afianzar su labor.

e) La publicación de las obras nacionales inéditas que a juicio de las academias oficialmente reconocidas merezcan este estímulo.

Durante este periodo, Samper Ortega logró:

- La inauguración del nuevo edificio, el 20 de julio de 1938.

- La publicación de la revista Senderos.

- La fundación de la Escuela de Bibliotecarios. Logró traer a la señorita Janeiro V. Brooks (directora adjunta del Colombus Memorial Library) para dar un curso en 1936.

- El aumento del número de canjes.

- El incremento del número de registros catalográficos.

- La creación de la Biblioteca Infantil.

- La construcción del Teatro anexo.

- La inauguración de la Sección de cinematografía educativa.

- Apertura de la Exposición Internacional del Libro.

- La impresión de una serie de cartillas de divulgación sobre botánica, cultivos, puericultura, higiene, dibujo, alimentos y otras materias, adaptadas a la mentalidad campesina, con una biblioteca de cien autores colombianos y una serie de manuales referentes a distintas industrias, las cuales forman la base de las bibliotecas aldeanas.

- La apertura del Archivo Nacional. 


\section{Componente patrimonial}

Este proyecto ha permitido generar una reflexión sobre el valor simbólico y patrimonial de este tipo de fuentes que son parte de la cultura impresa de nuestro país. La historia se ha construido especialmente a partir de fuentes consideradas tradicionales. En contraste, objetos e imágenes (entre otros) se estiman y valoran tan solo como fuentes secundarias. En este caso, el objeto es la fuente primaria y se debe reconocer su valor simbólico, patrimonial y comunicacional, ya que no solo son un vestigio de una época, sino que son parte de un fragmento de la historia de la Biblioteca Nacional de Colombia y de la historia de la cultura material de nuestro país.

Los sistemas o medios de impresión, y cada uno de sus componentes, han contribuido a la construcción de discursos sobre la Nación, el ciudadano y una determinada ideología, ubicada históricamente. En ese sentido, la reflexión sobre estos objetos en la categoría de lo patrimonial es necesaria, ya que es fundamental aportar a la identificación del patrimonio gráfico colombiano:

(...) En el interior de este vacío simbólico vive una gran variedad de objetos y de saberes: máquinas, utensilios, herramientas, gestos y técnicas tradicionales que dieron forma y realidad a los productos de la cultura escrita. Se trata de máquinas impresoras, máquinas tipográficas, matrices, clisés, mobiliario diversificado, máquinas y herramientas específicas, cajones, componedores, linotipos y toneladas de tipos móviles que, por no tener su estatuto patrimonial definido, son, a menudo, tratados como basura y chatarra. Sometidas al comercio, muchas veces ilegal, del reciclaje, fuentes y fuentes de tipos móviles del pasado se transforman en plomo derretido. La ausencia de estos objetos -destruidos por la negligencia- trae en sí mismo la amenaza del apagón de los sistemas de producción y circulación de la cultura escrita. Contraponiéndose a la enorme diversidad de elementos materiales que constituyen estos sistemas, pocos son los objetos que han resistido a la indiferencia con la que las instancias patrimoniales los divisan. Más allá de la concreción de sus objetos, ese mismo patrimonio sostiene la historia inmaterial de las técnicas, todavía más difícil de ser captada. En este sentido, se trata, también, del cotidiano de las prácticas, del gesto del tipógrafo, de los dedos del linotipista, del movimiento de la hoja de papel en una máquina impresora, del ballet ágil y ritmado del impresor, del sonido secuencial del montaje de la rama tipográfica, del secreto del encuadernador y de muchos gestos más... (Utsch, 2018)

La memoria colectiva de nuestro país se articula con los vestigios de la cultura material y los elementos, prácticas y usos del patrimonio gráfico, los cuales son el reflejo de nuestros saberes históricamente constituidos.

\section{A manera de conclusión}

Los discursos asociados a la construcción de la historia del Diseño gráfico colombiano han estado mediados por enfoques hegemónicos, como las visiones europea y norteamericana, que desconocen elementos del discurso local, y de la cultura local, con lo cual se ha propiciado una visión de la historia colombiana en general y de la del Diseño gráfico, donde se desconocen 
otras formas de hacer Diseño, desde las tradiciones, los objetos, los autores, las perspectivas de género que enriquecieron los procesos que a su vez permitieron el desarrollo local, caracterizado por la diversidad.

Es urgente generar estudios que permitan el reconocimiento y la valoración de los saberes, oficios y prácticas tradicionales, evidentes en la cultura material e inmaterial.

Por otro lado, es necesario hablar de los elementos que constituyen el patrimonio gráfico colombiano, ya que conceptualmente la noción de lo patrimonial ha estado vinculada con concepciones que impiden la validación de ciertos elementos, como por ejemplo los objetos que hacen o hicieron parte de los procesos editoriales. Este es el caso de la colección de clisés, que se convirtieron en objeto de estudio del proyecto: "imprenta del sótano: colección de clisés de la Biblioteca Nacional de Colombia”, sobre los cuales había una mirada que no los encajaba en los estudios e investigaciones académicas tradicionales, pero que luego se insertan en una cadena de valor muy importante que tiene que ver con los procesos de producción, circulación y apropiación de los medios editoriales.

Entonces, el objeto relegado llamado clisé de impresión permite la reconstrucción de una época muy importante para la historia Nacional, a través de la historia de la Biblioteca Nacional de Colombia. Son piezas en metal que fueron diseñadas y pensadas para producir discursos visuales, que a su vez relacionados con textos y en el marco de la relación entre significantes y significados, propios de los libros, como 'productos editoriales, pusieron en circulación una serie de ideologías, relacionadas con la época, como la idea del gobierno de turno sobre la necesidad de educar al pueblo a través de procesos más democráticos, como en el caso de la biblioteca Aldeana, o los contenidos culturales de la Revista del Archivo Nacional, o la propuesta gráfica y de vanguardia de la Revista Senderos.

El diseño gráfico colombiano, es un campo relativamente joven, sin embargo, según historiadores del diseño, este tiene sus antecedentes más importantes desde las primeras manifestaciones de la humanidad, en el caso local ha estado acompañando la construcción del discurso histórico del país, hace parte de su memoria y a través de sus objetos, procesos, entre otros. Constituye parte importante del patrimonio gráfico nacional.

Al reconocer este campo como parte del discurso histórico, se reconocen todos los elementos de producción de sentido desde su producción material e inmaterial y se puede entender y valorar cómo las prácticas culturales en las que se insertan los productos del diseño gráfico, ponen en circulación, a través de sus significantes, modelos de identificación, subjetividades, cuerpos, sujetos, entre otros.

Esto es explícito en el estudio de los intereses comunicativos de las publicaciones producidas por el Departamento editorial de la Biblioteca Nacional de Colombia, sus enfoques formales, sus intenciones informativas, sus componentes gráficos, entre otros, la indagación por los aspectos formales, cromáticos, tipográficos, compositivos y espaciales que definen las imágenes. Este proyecto ha permitido incluso entender las complejidades sobre los sistemas de lecto escritura y su relación con las diferentes posturas políticas, otras miradas frente a las historias oficiales de la Biblioteca Nacional de Colombia, el reconocimiento de los primeros ilustradores gráficos, como es el caso de Sergio Trujillo Magnenat. 
Finalmente, como se planteó desde el comienzo, los clisés de impresión son objetos susceptibles de investigación histórica, que permiten ampliar las posibilidades de trabajar con fuentes documentales que al mismo tiempo son documentos históricos con los que se puede reconstruir el pasado y el presente de la sociedad colombiana y en este caso particular, la reconstrucción del pasado de la historia del diseño y las publicaciones periódicas.

\section{Referencias}

Aicher, O. (2004). Tipografía. Valencia: Campgràfic. Alpers, Svetlana. (1987). El arte de describir. El arte holandés en el siglo XVII. Madrid: Herman Blume.

Armstrong, Hellen. (2009). Graphic Design Theory. New York: Princeton Architectural Press.

Díaz, C. J. (2005). El pueblo, de sujeto dado a sujeto político por construir: El caso de la campaña de cultura Aldeana en Colombia (1934-1936). Bogotá, Colombia: Universidad Pedagógica Nacional.

Eisenstein, E. L. (2010). La imprenta como agente de cambio. México, F.C.: Fondo de Cultura Económica.

Florez de Ocariz, Juan. (1994). Genealogías del Nuevo Reino de Granada. Libro primero. Volumen II. Segunda edición. Bogotá: Prensas de la Biblioteca Nacional. Gruzinski, Serge. (1994). La guerra de las imágenes. De Cristóbal Colón a Blade Runner. México: Fondo de Cultura Económica.

Gruzinski, Serge. (2007). El Pensamiento Mestizo. Cultura amerindia y civilización del Renacimiento. España:

Editorial Paidós.
Hernández de Alba, Guillermo \& Carrasquilla Botero, Juan. (1977). Historia de la Biblioteca Nacional de Colombia. Bogotá: Instituto Caro y Cuervo.

Herrera C., Martha. (1993). Historia de le educación en Colombia. La república liberal y la modernización de la educación, 1930-1946. Recuperado de: http:// www.pedagogica.edu.co/storage/rce/articulos/ rce26_o6ensa.pdf

Meggs, Philip. (1991). Historia del diseño gráfico. México: Trillas.

Ministerio de Educación Nacional. (1941). Memoria 1941. Tomo I. Bogotá: Prensas de la Biblioteca Nacional.

Troconi, Giovanni. (2010). Diseño gráfico en México 100 años: 1900-2000. México: Artes de México.

Utsch, Ana. (2018). Conferencia: Patrimonio gráfico en red. Bogotá: Universidad Jorge Tadeo Lozano. 